\title{
Responsabilidade civil do Estado no direito brasileiro: Há princípio único regulador?
}

\author{
Elizeu de Moraes Corrêa*
}

Sumário: 1.Noção preliminar; 2.Espécies de responsabilidade; 3.Nota sobre a evolução do tema; 4.Considerações sobre o regime da responsabilidade pública no direito brasileiro.

\section{Noção preliminar}

A responsabilidade patrimonial do Estado pode ser conceituada como a obrigação que lhe incumbe de reparar economicamente os danos lesivos à esfera juridicamente garantida de outrem e que lhe sejam imputáveis em decorrência de comportamentos unilaterais, lícitos ou ilícitos, comissivos ou omissivos, materiais ou jurídicos, ${ }^{1}$ vale dizer, é o dever jurídico que se impõe à Administração de reparar o dano causado a terceiros, gerado no desempenho ou omissão de suas atribuições. É que a atividade do Poder Público, como qualquer outra atividade, também pode ocasionar danos. Assim, a reparação destes danos e as condições em que isto efetivar-se-á, é tema próprio do direito administrativo.

Com efeito, cabe desde logo identificar a espécie de responsabilidade a ser tratada. Consigna Rivero, quando trata da responsabilidade do Estado,

* Mestre e Doutorando em Direito pela UFPR, Professor da Faculdade de Direito de Curitiba, Procurador do Estado junto ao Tribunal de Contas/PR.

1 Celso Antonio Bandeira de Mello, Elementos de Direito Administrativo, São Paulo, Malheiros, 1992, p. 320.

R. Fac. Direito, Curitiba, a.28, n.28, 1994/95, p.211-226 
que: a responsabilidade aqui encarada e uma responsabilidade civil: não poderia haver responsabilidade penal da Administração. ${ }^{2}$

Cumpre distinguir, desde logo, as espécies de responsabilidade e seus fundamentos, para a perfeita compreensão do tema.

\section{Espécies de responsabilidade}

Com o propósito de melhor embasar as conclusões do presente estudo, pode-se classificar a responsabilidade nas seguintes divisões: a) civil, penal e administrativa; $b$ ) direta e indireta; c) contratual e extracontratual; d) subjetiva e objetiva; e $e$ ) pública e privada. $^{3}$

a) Responsabilidade Civil, Administrativa e Penal: Com relação à primeira divisão, cabe esclarecer que a distinção entre a responsabilidade zivil e a criminal se fez sentir apenas durante o movimento codificador do jéculo XIX. Tunc assevera que nas sociedades primitivas as res-ponsabililades civil e penal eram provavelmente dois aspectos de um conceito unitário embora, consoante expressa Limongi França, por obra do imperador Gordiano, estabeleceu-se a distinção, quanto à morte de escravo, das sanções pela Lei Aquília e pela Lei Criminal. ${ }^{4}$

Segundo o relato de Cunha Gonçalves, as Ordenações Afonsinas e os Forais mostram bem que no antigo direito português não se concebia sequer uma responsabilidade civil que não fosse conexa da criminal. As multas, o confisco total ou parcial dos bens, eram penas. Não havia direito privado sobre tal matéria. Assim se chegou até o alvorecer do Século XIX e ao regime liberal $^{5}$

2 cian Kivero, Direito Administrativo, Trad. de Rogério Ehrhardt Soares, Coimbra, Almedina, 1981, p. 306.

3 Ver oportuna classificação formulada por: Carlos Alberto Bittar, Responsabilidade Civil nas Atividades Nucleares, São Paulo, RT, 1985, p.28

4 André Tunc, La Responsabilite Civile, Paris, Economica, 1981, p. 47; e R. Limongi França, As raízes da responsabilidade aquiliana., RT n ${ }^{\circ} 577$, p. 17.

5 Luiz da Cunha Gonçalves, Tratado de Direito Civil, São Paulo, Max Limonad, 1957,p. 464 
Os Mazeaud, visando sustentar a referida distinção, argüem que pouco importa que este ato, proibido pela lei penal, porque nocivo à sociedade, tenha ou não causado prejuizo a um particular (...) Ela (sociedade) se preocupa apenas com os danos que ela sofreu. Tudo mais é a responsabilidade civil: ela supõe não mais um prejuizo social mas um dano privado, a vítima não é mais toda a sociedade, mas um particular. ${ }^{6}$

Como ressalta Tunc, as responsabilidades civil e penal têm numerosas funções comuns, tais como a prevenção de condutas anti-sociais, satisfação da vítima, punição do autor do dano, e juntas elas podem intervir alternativa ou cumulativamente para assegurar o respeito do direito. Mas os objetivos são distintos. O objeto direto da ação civil é a indenização da vítima e o da ação penal é infligir uma sanção a qualquer que tenha descumprido a Lei. ${ }^{7}$

Se bem que os fins de prevenção, repressão e correção do infrator possam ser atribuídos indiretamente ao âmbito civil, eles retratam e fundamentam as razões da imposição de penas no âmbito penal.

Aliás, é esta a ressalva de Pontes de Miranda, quando diz que $o$ homem que causa dano a outrem, não prejudica somente a este, mas à ordem social; a reparação para o ofendido não adapta o culpado à vida social, nem lhe corrige o defeito de adaptação. O que faz é consolar o prejudicado com a prestação do equivalente, ou, o que é mais preciso e exato, com a expectativa jurídica da reparação. ${ }^{8}$

Este é o objetivo da responsabilidade civil: o de reintegrar a vítima do dano ao status quo ante, seja mediante a reparação do dano de modo direto, ou indiretamente, mediante uma compensação pecuniária pelo prejuízo sofrido.

Já quanto à responsabilidade penal, esta é fixada para atos que, dada a sua gravidade, são reprovados pelo meio social, com o estabelecimento de sanções penais, graduadas conforme sejam as infrações (tipos penais).

6 Henri et Leon Mazeaud, Traice Theorique et Pratique de la Responsabilité Civile Delictuelle et Contractuelle, Paris, Sirey, 1947, p. 2.

7 André Tunc, La Responsabilite..., op. cit., p. 48.

8 Pontes de Miranda, apud José de Aguiar Dias, Da Responsabilidade Civil, Rio de Janeiro, Forense, 1983, p. 8

R. Fac. Direito, Curitiba, a. 28, n.28, 1994/95, p.211-226 
Ressalve-se, contudo, que com a evolução do Direito, fruto das próprias transformações sociais, inserindo-se no ordenamento jurídico moderno as noções de interesses coletivos e difusos, não há como restringir, como apregoam os Mazeaud, os danos à sociedade como matéria exclusiva do âmbito penal, pois tal sistema é insuficiente e insatisfatório. Perante o Direito moderno, a sociedade sofre danos e pode exigir a reparação civil, independente dos mecanismos de prevenção e repressão de âmbito penal.

As noções e classificação de ilícito, embora adotadas para clarear a distinção em comentário, também não satisfazem totalmente, pois a responsabilidade pode decorrer de danos causados em atividades "lícitas".

O ilícito constitui a violação da norma jurídica. A categoria da norma jurídica, portanto, vai fixar a modalidade do ilícito, podendo ser civil, administrativo ou penal, conforme seja a natureza da norma violada.

Se a distinção entre responsabilidade civil e penal, embora fixada, encontra seus fundamentos díspares na doutrina, a diferenciação entre responsabilidade administrativa e penal, tem sido estabelecida por uma linha tênue, qual seja: a da gravidade da falta. É que na relação do indivíduo com o Poder Público (comunidade), há deveres assumidos e impostos para a harmonia do convívio social. Diante disto, a qualificação de certos atos considerados ilícitos, porque violadores de regras impostas coercitivamente, como administrativos ou penais, depende dos rumos e opções políticas do legislador, já que não há distinção na essência do dever jurídico secundário, senão na gradação e especificidade da sanção atribuída. É em razão disto que assistimos a constantes mutações no que refere à qualificação dos ilícitos, ora transformando-se ilícitos administrativos em crimes ou contravenções e a desqualificação de crimes em contravenções, ou ainda, para simples ilícitos administrativos. $^{9}$

A distinção é mais clara nas conseqüências, vez que a prática de ilícito administrativo implica na imposição pela Administração Pública de sanções administrativas, tais como, a multa, a interdição de atividades, embargos e destruição de coisas. ${ }^{10}$

9 Massimo Severo Gianini, Istituzioni di Diritto Amministrativo, Milano, Giuffrè, 1981, p. 451.

10 Hely Lopes Meirelles, Direito Administrativo Brasileiro, $7^{\mathrm{a}}$ ed., São Paulo, RT, 1979, p. 171. 
A responsabilidade administrativa, na expressão de Renato Alessi, resulta da violação dos deveres administrativos perante a administração, e que importa na aplicação de sanções administrativas pela autoridade administrativa em forma administrativa. ${ }^{11}$

Neste sentido, enquanto a responsabilidade civil cuida da reparação dos danos, visando a reconstituição ao estado anterior e a responsabilidade penal procura pela ressocialização do infrator pela prevenção e repressão, a responsabilidade administrativa procura impor sanções pela violação dos deveres administrativos que nos são inerentes enquanto cidadãos-administrados.

Contudo, há que se ressalvar que um mesmo fato pode consistir na responsabilidade civil, penal e administrativa do infrator, pois que estas, por seus próprios fundamentos, são distintas e independentes, vale dizer, são aplicáveis simultânea e isoladamente, sem que da aplicação de uma decorra, necessariamente a imposição das demais, ou a vedação a que outras sanções sejam também aplicadas.

A afirmativa pode, a princípio surpreender o jurista, porém, aproveitando o exemplo de Tunc, ${ }^{13}$ pode-se demonstrar que um mesmo ato (conduta imprudente do condutor de automóvel) que causa lesão a um transeunte, pode gerar a responsabilidade civil (danos suportados pela vítima), a responsabilidade penal (crime de lesão corporal) e a responsabilidade administrativa (violação de regra do Código Nacional de Trânsito). Não há que falar, pelos fundamentos supra apontados, em ilícita cumulação de responsabilidade ou dupla apenação ao infrator. ${ }^{14}$

11 RenatoAlessi, "Responsabilitá Ammnistrativa", in Novissimo Digesto Italiano, Torino, Ed. Torinex, vol. XV, 1968, p. 618.

12 RenatoAlessi, Responsabilitá..., op. cit., p. 618.

13 André Tunc, La Responsabilite..., op. cit., p. 48.

Sobre o assunto, Hely Lopes Meirelles, Direito... op. cit., p. 616, afirma que "como obrigação meramente patrimønaial, a responsabilidade civil independe da criminal e da administrativa, com as quais pode coexistir sem todavia se confundir."

14 Veja-se, também, o exemplo mencionado pelos Henri et Leon Mazeaud, Traité... op. cit., p. 2 e ss. Ver ainda: Maria Helena Diniz, Curso de Direito Civil Brasileiro, $2^{\mathbf{a}}$ ed., São Paulo, Saraiva, 1977, p.6, vol. 4; e Roberto Rosas, "Responsabilidade Civil e Criminal", in Enciclopédia Saraiva de Direito, vol. 65, p. 414 e ss.

R. Fac. Direito, Curitiba, a.28, n.28, 1994/95, p.211-226 
Por outro lado, é de se lembrar que o próprio Código Civil (art. 1525) estabelece a independência da responsabilidade civil da criminal. Evidente, porém, que a imbricação de tais responsabilidades dispensará, conforme 0 caso, o exaustivo procedimento probatório do fato nas 3 (três) esferas. Daí porque Antonio Chaves, comentando a parte final do referido artigo, assevera que uma coisa, porém, é certa: reconhecido um ato criminoso no juízo penal, não cabe mais qualquer discussão sobre o seu caráter ilícito. ${ }^{15}$

b) Responsabilidade Direta e Indireta: Com relação à segunda divisão, leva-se em conta o agente (pessoa ou coisa) que causou a ação danosa. Desta forma, quando a ação ou omissão é imputada ao próprio demandado, estamos diante da responsabilidade direta. De outro lado, se o dano advém de fato de terceiro ou de coisa sob a esfera jurídica de dependência do demandado, estamos diante da responsabilidade indireta. ${ }^{16}$

O fundamento da responsabilidade direta tem fulcro na idéia básica de que a responsabilidade é o corolário da liberdade e da racionalidade. ${ }^{17}$ No que toca à responsabilidade indireta, vamos buscar sua origem na responsabilidade noxal dos romanos. ${ }^{18}$

Enquanto na responsabilidade direta a regulamentação legal se insere nos princípios gerais pertinentes à matéria, para a responsabilidade indireta há normas especiais ou disposições específicas na própria codificação que a estabelece. No CCB encontramos, no artigo 1521, enumeração de casos de responsabilidade indireta, sendo que o princípio geral da responsabilidade direta encontra-se no artigo 159 do mesmo diploma legal. ${ }^{1}$

15 Antonio Chaves, Tratado de Direito Civil, São Paulo, RT, 1985, p. 49.

"CCB - Art. 1525: A responsabilidade civil é independente da criminal; não se poderá, porém, questionar mais sobre a existência do fato, ou quem seja o seu autor, quando estas questões se acharem decididas no crime."

16 Antonio Chaves, Tratado..., op. cit., p. 87.

17 Carlos Alberto Bittar, Responsabilidade Civil nas Atividades Nucleares, São Paulo, RT, p. 31, inspirando-se nas lições de Henri Fromageot.

18 R. Limongi França, As raizes..., op. cit., p. 12.

19 Assim dispõem os referidos dispositivos: "Art. 159. Aquele que, por ação ou omissão voluntária, negligência ou imprudência, violar direito, ou causar prejuízo a outrem, fica obrigado a reparar o dano", e "Art. 1521 - São também responsáveis pela reparação civil: I - Os pais, pelos filhos menores que estiverem sob seu poder e em sua companhia; II O tutor e o curador, pelos pupilos e curatelados, que se acharem nas mesmas condições; III - O patrão, amo ou comitente, por seus empregados, serviçais e prepostos, no 
A distinção é aqui relevante pois verificar-se-á que as normas constitucionais, antes de enunciarem um regime especial de responsabilidade como se tem propalado -, apenas estabelece uma responsabilidade de feição indireta, ao imputar às pessoas jurídicas de direito público a obrigação de responder pelos danos que seus agentes, nessa qualidade, causarem a terceiros.

c) Responsabilidade Contratual e Extracontratual: A distinção entre a responsabilidade contratual e extracontratual se faz quanto ao fato gerador da responsabilidade.

Será contratual se oriunda de inexecução de avença preestabelecida entre as partes, sendo o contrato, neste caso, a fonte de obrigação do qual exsurge a responsabilidade no seu descumprimento. O tratamento legal é também distinto, pois no caso da responsabilidade contratual esta é regulada nas disposições dos artigos 1056 e seguintes do CCB.

De outro lado a responsabilidade extracontratual, por muito tempo adstrita à responsabilidade aquiliana ou delitual, deriva do dever geral de não lesar a outrem (alterum non laedere). ${ }^{20}$ Não há vínculo anterior ao dano entre as partes. A fonte da responsabilidade é a lei, cuja inobservância traz ínsita a lesão a direito subjetivo de outrem.

Relativamente às conseqüências, pode-se dizer que há distinção quanto ao onus probandi, pois na responsabilidade contratual cumprirá ao devedor a prova de que cumpriu a obrigação ou de que não a cumpriu por motivo de caso fortuito ou força maior - causas excludentes de responsabilidade. $^{21}$

Há distinção, também, relativa à capacidade das partes, pois um contrato exige plena capacidade dos agentes, sob pena de nulidade e de não

exercício do trabalho que lhes competir, ou por ocasião dele (Art. 1522); IV - Os donos de hotéis, hospedarias, casas ou estabelecimentos, onde se albergue por dinheiro, mesmo para fins de educação, pelos seus hóspedes, moradores e educandos; V - Os que gratuitamente houverem partiçipado nos produtos do crime, até à concorrente quantia."

20 Sobre a doutrina moderna relativa à expressão, ver: Salvatore Pugliatti, "Alterum non laedere", in Enciclopédia del Diritto, vol. II, 1958, p. 98 e ss.

21 Sobre o assunto, entre outros: Carlos Roberto Gonçalves, Responsabilidade Civil, São Paulo, Saraiva, 1986, p. 20 e ss; Maria Helena Diniz, Curso..., op. cit., p. 89; e Carlos Alberto Bittar, Responsabilidade..., op. cit., p. 32. 
produzir efeitos indenizatórios. Já o ato do incapaz na esfera extracontratual pode ensejar a reparação nos moldes já vistos da responsabilidade indireta.

É de se ressalvar, contudo, que a distinção que acabamos de colocar não tem plena adoção dos'estudiosos da matéria. José Rubens Costa, aliás, mediante profunda pesquisa, demonstra as três principais correntes doutrinárias que se formaram sobre o assunto. ${ }^{22}$

Para a corrente unitária, assumida por Lefebvre e Grandmoulin, não há distinção entre a responsabilidade contratual e a delitual pois ambas derivam de culpa. As diferenças são apenas aparentes. Outros, da corrente dualista, como Sainctelette, de Page e Savatier, argüem que há diferença de natureza e de conseqüências, sustentando, inclusive, o uso da expressão garantia em relação à responsabilidade contratual. Por fim, a corrente eclética, promovida por Planiol e pelos Mazeaud, concilia as outras correntes apregoando que não há diferenças fundamentais e essenciais entre tais espécies de responsabilidade, mas tão somente com relação às suas conseqüências. ${ }^{23}$

d) Responsabilidade Objetiva e Subjetiva: A separação entre as responsabilidades objetiva e subjetiva se verifica a partir do fundamento legal em que se fulcram. Enquanto na responsabilidade subjetiva se perquire a respeito da culpa do agente, isto não ocorre com a responsabilidade objetiva, pois que independe da ocorrência de culpa e se baseia no risco.

A responsabilidade subjetiva foi, durante muitos anos, a regra própria das codificações, desde, como se pode perceber na evolução histórica da responsabilidade, a edição da Lex Aquilia, com o estabelecimento do princípio geral regulador da culpa. A responsabilidade objetiva vem sendo reconhecida, caso a caso, em leis especiais e esparsas, não como princípio geral, mas sim como exceção, nos casos em que a aplicação do sistema clássico de culpa implique em soluções injustas. ${ }^{24}$

Neste sentido, Trimarchi assevera que o princípio da responsabilidade por culpa se revela então insuficiente a resolver o problema dos danos

22 José Rubens Costa, "Da Responsabilidade Civil Contratual e Delitual", Revista Forense, vol. 256 , p. 116 e ss.

23 Sobre o assunto, ver também: José de Aguiar Dias, op. cit., p. 131.

24 Caio Mario da Silva Pereira, Instituições de Direito Civil, $3^{\mathrm{a}}$ ed., Rio de Janeiro, Forense, 1972, vol. III, p. 507. 
causados no exercício da indústria. Não podendo se evitar tais danos, se quer ao menos garantir o ressarcimento e parece justo realizar tal resultado tendo como responsável o empreendedor. ${ }^{25}$ Esboça-se, então, o princípio cristalizado no brocardo ubi emolumentum, ibi onus, em que se assevera que aquele que tira proveitos da atividade, deve arcar com os ônus e o risco desta atuação. Vale dizer, o risco em ser compelido a indenizar determinados danos é a contrapartida do lucro ou proveito econômico que 0 homem retira de certas atividades. ${ }^{26}$

A discórdia doutrinária, por muito tempo objeto de acalorados debates e obras de profunda pesquisa, residia exatamente na tentativa de construir para a doutrina da responsabilidade um único princípio regulador, culpa ou risco. ${ }^{27}$

Mas, como ressalvou Starck, trata-se de um falso dilema pois deve-se olhar e ter em conta os interesses e os direitos da vítima e não, como é corrente, analisar tão somente a situação jurídica do autor do dano. Avança, o renomado mestre da Faculdade de Direito e Ciências Econômicas de Lyon, por estabelecer que o homem possui direitos como à vida, à integridade corporal e, de uma maneira geral, ao gozo pacífico de seus mais diversos direitos e liberdades e à sua segurança. E ter estes direitos implica em ter meios de os proteger e de os garantir contra os empreendimentos de outrem. ${ }^{28}$

Por ocasião da elaboração do Projeto de Código Civil, ressaltou Miguel Reale com relação à indagação: Responsabilidade subjetiva ou responsabilidade objetiva? Não há que fazer esta alternativa. Na realidade as duas formas de responsabilidade se conjugam e se dinamizam. ${ }^{29}$

Aliás, consoante reporta Antonio Chaves, é este o sistema adotado pelo nosso atual Código Civil, lembrando as afirmações de destacados

25 Pietro Trimarchi, Rischio e Responsabilità Oggetiva, Milano, Giuffrè, 1961.

26 Ver, a propósito: B. Starck, "Domaine et Fondement de la Responsabilité Sans Faute", Revue Trimestrielle de Droit Civil, Paris, Sirey, Vol. LVI, 1958/4, p. 478.

27 Sobre o assunto e por todos: Wilson Melo da Silva, Responsabilidade sem Culpa, São Paulo, Saraiva, 1974.

28 B. Starck, Revue Trimestrielle de Droit..., op. cit., p. 501.

29 Miguel Reale, "Diretrizes Gerais sobre o Projeto de Código Civil". In Estudos de Filosofia e Ciência do Direito, São Paulo, Saraiva, 1978, p. 176.

R. Fac. Direito, Curitiba, a.28, n.28, 1994/95, p.211-226 
membros das comissões redatora e revisora do Projeto do Código Civil. É de Justiniano de Serpa, por exemplo, a declaração de que todo dano deve ser reparado, independente de culpa ou dolo; de Gonçalves Maia: o princípio geral de nosso Direito é: danificou, indeniza; de Clóvis Beviláqua: a ordem jurídica impõe um dever geral e predominante de respeitar cada um a esfera da atividade jurídica dos outros. E esse dever é tão imperioso, pela necessidade de manter-se o equilíbrio da organização social, que exige reparação por parte de todo aquele que o viola, ainda quando se considera autorizado e de Alcino de Paula Salazar: a doutrina que triunfou na elaboração do Código foi a de que todo dano deve ser ressarcido, independentemente de culpa ou dolo. ${ }^{30}$

Desta forma, não resta dúvida de que o sistema jurídico brasileiro assumiu tanto a responsabilidade subjetiva quanto a objetiva. Quanto àquela, o fez expressamente na forma já comentada no artigo 159 do CCB. Quanto à objetiva, tem contemplado em legislação especial, estabelecendo que se opera independentemente da existência de culpa.

Quanto à distinção, muito embora alguns autores busquem ainda um princípio único para a responsabilidade, prevalece como uma das mais importantes para o estudo e compreensão deste instituto jurídico.

e) Responsabilidade Pública e Privada: Já a última separação que propusemos classificar diz respeito à responsabilidade civil pública e privada, ${ }^{31}$ sendo a primeira relativa a obrigação de reparar imputada a entes da administração pública e a segunda concernente a pessoas físicas e pessoas jurídicas de direito privado.

Muito embora a distinção não envolva controvérsia, é de se ressaltar que a responsabilidade civil ou patrimonial do Estado (Administração Pública) nem sempre foi admitida, como se verá a seguir.

30 Antonio Chaves, Tratado..., op. cit., p. 71.

31 Sobre o assunto, podem ser consultados os segintes autores: Renato Alessi, "Responsabilità Civile della Pubblica Amministrazione", I: Novíssimo Digesto Italiano, Torino, Ed. Torinese, vol. 15, 1968, p. 660-667; Renato Alessi, L'illicito e la Responsabilità Civile degli Enti Publici, Milano, Giuffrè, 1972; e José Joaquim Gomes Canotilho, O problema da responsabilidade do Estado por Atos Licitos, Coimbra, Almedina, 1974. 


\section{Nota sobre a evolução do tema}

A possibilidade dos cidadãos (administrados) obterem a reparação pelos danos imputáveis ao Estado (agentes e concessionários) resulta da própria evolução do Estado, e reflete, como assevera Rivero, uma certa forma de civilização. ${ }^{32}$

Com efeito, conforme relata Hely Lopes Meirelles, sob o domínio dos governos absolutos negou-se a responsabilidade do Estado, secularizada na regra inglesa da infalibilidade real - The King can do no wrong extensiva aos seus representantes; sob a influencia do liberalismo, assemelhou-se o Estado ao individuo, para que pudesse ser responsabilizado pelos atos culposos de seus agentes; finalmente, em nossos dias, atribuiuse à Administração Pública uma responsabilidade especial de direito público. ${ }^{33}$

Neste sentido, a influência do direito francês foi importante, ao identificar atos de gestão - em que o Estado não agia com soberania -, e admitir, mesmo diante de ausência de texto normativo específico, que o Estado é responsável quanto aos danos causados aos particulares, por atos dos agentes de serviço público, como se definiu no célebre aresto Blanco. ${ }^{34}$

A fase da irresponsabilidade do Estado está inteiramente superada, com as novas normas em vigor tanto nos Estados Unidos da América do Norte quanto na Inglaterra, últimos redutos da mencionada doutrina.

A responsabilidade do Estado está umbilicalmente ligada à própria submissão do Estado ao Direito, vale dizer, faz parte do rol de direitos e garantias fundamentais que alcançou o cidadão como forma de limitação do Poder. Neste sentido, são lúcidas as palavras de Bandeira de Mello, ao afirmar que a trabalhar-se com categorias puramente racionais dedutivas, a responsabilidade estatal é simples corolário da submissão do Poder Público ao Direito (...) a partir do instante em que se reconheceu que todas as pessoas, sejam elas de direito privado, sejam de direito público, encontram-se, por igual, assujeitadas à ordenação jurídica, ter-se-ia que aceitar,

32 Jean.Rivero, Direito..., op. cit., p. 305.

33 Hely Lopes Meirelles, Direito Administrativo..., op.cit., p. 616.

34 Jean Rivero, Direito..., op. cit., p. 308

R. Fac. Direito, Curitiba, a.28, n.28, 1994/95, p.211-226 
a bem da coerência lógica, o dever de umas e outras - sem distinção responderem pelos comportamentos violadores do direito alheio em que incorressem. ${ }^{35}$

Da irresponsabilidade do Estado, evoluiu-se à admissão da responsabilidade do funcionário, se 0 ato lesivo pudesse ser diretamente relacionado a um comportamento pessoal por ele exercido. Neste período, pode-se afirmar que a responsabilidade estatal era regida pelos mesmos parâmetros da responsabilidade privada. A culpa - fundamento geral da responsabilidade -, haveria de ser identificada no comportamento pessoal do agente público que causou o dano indenizável. É, contudo, no debate travado no direito francês, acerca do foro competente para processar e julgar as ações de responsabilidade contra o Estado, que este assunto ganhou nova dimensão. Ao afirmar que as disposições do direito privado são inaplicáveis em matéria de responsabilidade da Administração, porque o problema a resolver não é o mesmo que em matéria de responsabilidade dos particulares, definiu-se a competência da jurisdição administrativa (Conseil d'Etat).

No já citado aresto Blanco, assim decidiu o Tribunal:

a responsabilidade, que pode incumbir ao Estado pelos danos causados aos particulares pelo fato das pessoas que ele emprega no serviço público, não pode ser regida pelos principios que são estabelecidos no Código Civil, pelas relações de particular perante particular; esta responsabilidade não é nem geral, nem absoluta; ela tem suas regras especiais que variam segundo as necessidades do serviço e a necessidade de conciliar os direitos do Estado com os interesses privados ${ }^{36}$

Estava preparado, portanto, o terreno para a criação de uma responsabilidade pública, distinta da noção até então assente de que l'Etat ne pouvant mal faire, ne pouvait être responsable. Dissociava-se, portanto, a noção de culpa, que lhe imprime o regime privado, para uma noção de falta de serviço, visto o Estado muito mais como um prestador de serviços do que como um Poder. Cria-se, então, uma responsabilidade estatal fundada na noção de mau funcionamento do serviço(mauvais

35 Celso Antonio Bandeira de Mello, Elementos..., op. cit., p. 325.

36 Francis-Paul Bénoit, Le Droit Administratif Français, Paris, Dalloz, 1968, p. 673 
fonctionnement du service), forma publicitada da noção de culpa-negligência ou falta (faute). ${ }^{37}$

A construção francesa da teoria da falta do serviço público (mau funcionamento do serviço; não funcionamento do serviço; e funcionamento do serviço tardiamente) se deve, conforme asseveram Duez e Debeyre, a dois fenômenos: a extensão da competência dos Tribunais Administrativos na matéria, com o abandono da distinção dos atos de autoridade e de gestão e o abandono da competência judiciária em matéria de responsabilidade comunal (municipal); e a multiplicação das ações de responsabilidade perante o Conselho de Estado, o que permitiu a consolidação de sua doutrina ${ }^{38}$ e sua influência inclusive no direito brasileiro.

A admissão do dever de reparar, independente da demonstração da falta de serviço, foi o passo seguinte na construção da jurisprudência do Conselho de Estado Francês. Esta posição, - a da teoria do risco administrativo -, adotada em caráter complementar e secundário, apenas se fez necessária em situações em que a teoria da falta do serviço se demonstrava injusta perante a vítima de danos promovidos pela atividade pública, pelo que se prestigiou o princípio da equidade e principalmente, o da isonomia dos indivíduos frente aos ônus e encargos sociais. Em algumas situações, portanto, basta a demonstração do nexo de causalidade entre o dano sofrido e a ação ou omissão da Administração para que emirja, para esta, o dever de indenizar, como é o caso de danos causados por explosivos. Além do mais, o dano indenizável deve ser revestido do caráter especial, anormal, e excepcional, suscetível de justificar a sua distribuição a todos os membros da comunidade. ${ }^{39}$

Disto decorre a afirmação de que a teoria do risco administrativo apenas excepcionalmente deve ser admitida, inocorrendo, como sugerem alguns autores, que a evolução histórica da responsabilidade pública tenha culminado com a prevalência de uma teoria e a aplicação de um princípio único regulador.

37 Francis-Paul Bénoit, Le Droit \$., op. cit., p. 677

38 Paul Duez et Guy Debeyre, Traité de Droit Administrati,. Paris, Dalloz, 1952, p. 418

39 Fernando Andrade de Oliveira, "Responsabilidade Civil do Estado por fatos da Administração Pública", Revista da Associação dos Magistrados do Paraná, Curitiba, Juruá, 1980 (20), p. 314.

R. Fac. Direito, Curitiba, a.28, n.28, 1994/95, p.211-226 


\section{Considerações sobre o regime da responsabilidade pública no direito brasileiro}

O Brasil, por certo, recebeu profunda influência do direito administrativo francês, alcançando, dentre os doutrinadores e nos nossos Tribunais, a mesma evolução conceitual daquele direito. Há, contudo, que se frisar, que alguns autores de nomeada e respeitáveis juizes, considerando o advento da Constituição de 1946 (art. 196), cujo texto foi posteriormente reproduzido, com algumas alterações nas Constituições posteriores, alegam a assunção pelo direito brasileiro da teoria do risco administrativo, como regra geral. Sobre o assunto, o eminente Themístocles Cavalcanti asseverou que não preferiu a Constituição, nenhuma das doutrinas existentes sobre a responsabilidade civil do Estado, exigiu apenas, que o funcionário tenha agido no exercício de suas funções. ${ }^{40}$

É que o texto constitucional estabelece a responsabilidade do Estado por ato dos seus prepostos - os agentes públicos - e estabelece o princípio da ação regressiva, nos casos de culpa pessoal do servidor. Nada afirma com relação à incidência do dever de reparação, independentemente da existência de culpa, seja ela considerada na falta do serviço público, seja com relação à culpa pessoal do servidor.

Analisando o regime de responsabilidade civil do Estado nos julgados de nossos tribunais superiores, a opinião de Caio Tácito, é a de que o sistema que encontra ressonância na jurisprudência brasileira é o da culpa administrativa, reservando-se o principio do risco aos casos excepcionais consagrados em lei. ${ }^{41}$

Do que vem de ser dito, se verifica que não há um princípio único regulador no que refere à responsabilidade civil do Estado. Como bem acentua Cirne Lima, a culpa e o risco formam as bases essenciais da responsabilidade da administração pública pelo dano decorrente do fato de seus agentes, ou do fato das coisas a seu serviço. A culpa abrange, porém, a maior extensão desse setor das relações jurídicas da adminis-

40 Fernando Andrade de Oliveira, "Responsabilidade...", op. cit., p.315.

41 CaioTácito, Tendências atuais sobre a responsabilidade civil do Estado, RDA, vol. 55, p. 262. 
tração. O risco constitui fundamento excepcionalmente estabelecido à responsabilidade da administração. ${ }^{42}$

Neste sentido, não cabe rotular como objetiva a responsabilidade civil do Estado, nem tampouco admitir-se que há um princípio único regulador desta responsabilidade. A legislação infra-constitucional ao estabelecer, em casos específicos a responsabilidade independente da existência de culpa, traz a presunção oposta, ou seja, a regra é o princípio da culpa, porém, excepcionalmente, pode-se fixar a denominada responsabilidade objetiva. Neste sentido, também, a própria norma constitucional, eis que quando o legislador quer prescindir do elemento culposo, o faz expressamente, como se vê no art. 21, inciso XXIII, alínea."c" da Constituição Federal de 1988. A redação do art. 37, $\S 6^{\circ}$ da Carta Magna, ao contrário de pressupor a objetivação da responsabilidade estatal, está mais própria à fixação da responsabilidade indireta do Estado por atos dos seus agentes, assumindo a teoria da representação, quando identifica na relação de preposição - Poder Público/agente - quem se responsabiliza pelos eventuais danos praticados.

O assunto não está pacificado, eis que singelas interpretações, levam a equivocada conclusão de estabelecimento de princípio único regulador, o que não se traduz na jurisprudência do Excelso Supremo Tribunal Federal, que tem identificado, como regra geral, o elemento culposo, seja a falta do serviço, seu retardamento ou aquele procedido de modo imperfeito, para fixar a responsabilidade estatal, seguindo a clássica doutrina e jurisprudência francesa.

De todo modo, a polêmica é ainda viva, consolidada nas teses da culpa administrativa, presumida pela falta, mau funcionamento ou retardamento do serviço; do risco administrativo, em que o fato do serviço, por injusto ou ilegal gera o dever de indenizar; e do risco integral, quando o Estado deve indenizar todo e qualquer dano provocado por ato da administração.

A Constituição da República Federativa do Brasil, recentemente promulgada, estabelece em seu Artigo $37, \S 6^{\circ}$ que As pessoas jurídicas de direito público e as de direito privado prestadoras de serviços públicos responderão pelos danos que seus agentes, nessa qualidade, causarem a terceiros, assegurado o direito de regresso contra o responsável nos casos de dolo ou culpa.

42 Ruy Cirne Lima, Principios de Direito Administrativo, São Paulo, RT, 1982, p. 198 e ss.

R. Fac. Direito, Curitiba, a.28, n.28, 1994/95, p.211-226 
tração. O risco constitui fundamento excepcionalmente estabelecido à responsabilidade da administração. ${ }^{42}$

Neste sentido, não cabe rotular como objetiva a responsabilidade civil do Estado, nem tampouco admitir-se que há um princípio único regulador desta responsabilidade. A legislação infra-constitucional ao estabelecer, em casos específicos a responsabilidade independente da existência de culpa, traz a presunção oposta, ou seja, a regra é o princípio da culpa, porém, excepcionalmente, pode-se fixar a denominada responsabilidade objetiva. Neste sentido, também, a própria norma constitucional, eis que quando o legislador quer prescindir do elemento culposo, o faz expressamente, como se vê no art. 21, inciso XXIII, alínea."c" da Constituição Federal de 1988. A redação do art. 37, $\S 6^{\circ}$ da Carta Magna, ao contrário de pressupor a objetivação da responsabilidade estatal, está mais própria à fixação da responsabilidade indireta do Estado por atos dos seus agentes, assumindo a teoria da representação, quando identifica na relação de preposição - Poder Público/agente - quem se responsabiliza pelos eventuais danos praticados.

O assunto não está pacificado, eis que singelas interpretações, levam a equivocada conclusão de estabelecimento de princípio único regulador, o que não se traduz na jurisprudência do Excelso Supremo Tribunal Federal, que tem identificado, como regra geral, o elemento culposo, seja a falta do serviço, seu retardamento ou aquele procedido de modo imperfeito, para fixar a responsabilidade estatal, seguindo a clássica doutrina e jurisprudência francesa.

De todo modo, a polêmica é ainda viva, consolidada nas teses da culpa administrativa, presumida pela falta, mau funcionamento ou retardamento do serviço; do risco administrativo, em que o fato do serviço, por injusto ou ilegal gera o dever de indenizar; e do risco integral, quando o Estado deve indenizar todo e qualquer dano provocado por ato da administração.

A Constituição da República Federativa do Brasil, recentemente promulgada, estabelece em seu Artigo $37, \S 6^{\circ}$ que As pessoas jurídicas de direito público e as de direito privado prestadoras de serviços públicos responderão pelos danos que seus agentes, nessa qualidade, causarem a terceiros, assegurado o direito de regresso contra o responsável nos casos de dolo ou culpa.

42 Ruy Cirne Lima, Principios de Direito Administrativo, São Paulo, RT, 1982, p. 198 e ss..

R. Fac. Direito, Curitiba, a.28, n.28, 1994/95, p.211-226 
O texto, sem dúvidas, veio aprimorar a redação do anterior Artigo 107 da Emenda Constitucional n ${ }^{\circ} 01$ de 17 de outubro de 1969, que tratava da responsabilidade das pessoas jurídicas de direito público, ${ }^{43}$ incorporando, à sua redação, o que a doutrina e jurisprudência pátrios vinham afirmando, no sentido de estender a responsabilidade estatal aos danos causados por agentes privados que prestam serviços públicos por delegação do Poder Público. Entretanto, nada fixou quanto à opção do legislador constituinte por esta ou aquela teoria, fato que demonstra a suficiência do sistema até aqui adotado de fixar-se como regra geral a teoria da culpa administrativa, e em casos excepcionais a teoria do risco administrativo.

Concluindo, pode-se afirmar que a responsabilidade patrimonial do Estado por danos que seus agentes, nesta qualidade, causem a terceiros, tem as seguintes características: é uma responsabilidade civil, pois visa a reparação dos danos causados, vale dizer, restabelecer o quanto possível o status quo ante; trata-se de responsabilidade indireta, de vez que responde o Estado (proponente) por ato de seus agentes (prepostos), podendo deles de ressarcir se demonstrar culpa pessoal; e fundamenta-se, não em um único princípio regulador (culpa ou risco), porém num sistema que consiste na aplicação da teoria da falta do serviço público (responsabilidade subjetiva-pública) como regra geral, e na teoria do risco administrativo (responsabilidade objetiva) em situações excepcionais, conforme indique o sistema normativo vigente.

43 Assim dispunha o texto Constitucional:

"Art. 107 - As pessoas jurídicas de direito público responderão pelos danos que seus funcionários, nessa qualidade, causarem a terceiros.

Parágrafo Único: Caberá ação regressiva contra o funcionário responsável, nos casos de culpa ou dolo." 